Yin $\mathrm{CHENG}^{1,2^{*}}$ and Jichao $\mathrm{XU}^{1}$

\title{
MODEL OF ENVIRONMENTAL MANAGEMENT SCIENCE BASED ON CIRCULAR ECONOMY THEORY
}

\begin{abstract}
The resources of a country are limited, and people must consider the important issue of how to make use of these limited material resources to create major economic value for humans. The theory of the circular economy has been proposed, which relies on scientific model research to create economic development that is more in line with people's concept of environmental management. The circular economy is characterised by resource conservation, recycling, coordination, low development, high utilization and low emissions. All material and energy use is reasonable, and sustainable land use minimises the influence of economic activities on the natural environment. Based on the theory of the circular economy, this paper studies the model of environmental management science. This paper analyses the mining development mode, the mechanism of the circular economy, and green logistics research based on circular economy theory and then applies statistical analyses to the two models. It summarises the development mode and the mechanism of the mining circular economy based on the current mineral resource development and utilization situation and the environmental problems in China. An innovative mode mechanism for mining circular economy development is proposed that can provide a value evaluation standard for social development. Through the above research, it is found that the use of circular economy theory can not only help make effective use of resources but also provide a new way to improve the gross national product.
\end{abstract}

Keywords: circular economy theory, mining development mode, green logistics research, environmental management science

\section{Introduction}

The concept of a circular economy stems from people's consideration of the ecological environment and quality of life [1]. Some experts and scholars have observed that "on the one hand, mankind is creating a high level of civilization, on the other hand, it is destroying the existing civilization". American economists believe that the earth is an isolated system in the universe, such as a spaceship. Their common feature is that the human beings living in them constantly consume their limited internal resources and change their internal environment. China advocates a path of sustainable development, which should not only meet the needs of the present generation but also not impair the ability of future generations to meet their own needs. Developed countries have taken the lead in developing circular economies, and have thereby opened economic distance from China. China should also see

\footnotetext{
${ }^{1}$ School of Management, Northwestern Polytechnical University, Xi'an 710129, Shaanxi, China, ORCID: 0000-0002-8261-1838

${ }^{2}$ Queen Mary University of London Engineering School, Northwestern Polytechnical University, Xi' an 710129, Shaanxi, China, email: jichaoxu@ gmail.com, ORCID: 0000-0001-6718-7242

*Corresponding author: julychristine@163.com
} 
the advantages of the circular economy in realising resource savings, reducing environmental pollution and realising sustainable development. This model aims to obtain an in-depth understanding of the development situation of the circular economy in developed countries and combine it with the actual development situation of the circular economy in China to form a comprehensive and in-depth sustainable development model, better build a harmonious society, and lay a solid foundation for China's decisive achievement of a moderately prosperous society.

Mineral resources are non-renewable. They are gifts given to us by nature. In the past, China's economy was inseparable from the destruction of environmental resources, for which China also paid a heavy price. China's relative lack of resources, coupled with uncontrolled exploitation and utilization of these resources by humans, means that its only material resources [2] are scarce. Over the past two years, China has entered a new high growth period, and the heavy chemical industry is an obvious component of this growth. With the development of the manufacturing industry [3] and the unlimited extension of the industrial chain, the demand for resources presents overall explosive growth. Since 2004, China's coal prices, coke prices, crude oil prices and refined oil prices have risen sharply, showing the excessive consumption of chemical industry resources in China. In addition, although the loss rate, ore dilution rate and recovery rate of dressings and smelting have greatly improved in recent years, there is still a certain gap compared with the advanced levels achieved abroad. Studying the model of mining development is of great significance to the development of heavy industry in China.

The concept of green logistics [4] has existed in China for a long time within both the government and the enterprise. Currently, many enterprises are environmentally aware. Green product production and green consumption awareness have been widely accepted by enterprises and the public. Because the logistics industry in China started late, enterprises play an important role in modern logistics. When beginning to construct an enterprise logistics system, it is necessary to reduce costs and improve efficiency and efficiency standards. Because of the lack of theoretical guidance, China's domestic [5] green logistics service level is still in its infancy. Many enterprises implement green logistics and engage in dynamic selection.

There must be a clear guiding ideology for carrying out environmental science research [6]; that is, environmental scientific research must offer suggestions to solve outstanding environmental problems for scientific environmental management. According to this guiding ideology, the research topics are determined, the key problems to be solved are organised, and the application of achievements is promoted. In the past, China's environmental protection work has been characterised by great achievements through hard work and rapid development. Now, an important problem for China's environmental protection workers is having environmental decision-making be scientific and reasonable, conform to the national conditions, and realise scientific environmental management so that those involved can fulfil their duty in the construction of the four modernizations. Environmental management science research must provide suggestions for solving outstanding environmental problems and thereby serve scientific environmental management. Specifically, it must drive the technological development of enterprises to control pollution sources, conduct extensive environmental scientific research, cooperate to address key problems, implement policies to promote the development of environmental protection science and technology, and realise scientific environmental decision-making 
[7]. China can better analyse the current situation of its environmental resources, make rational use of resources, and create greater value from limited resources.

How to make the best use of limited material resources [8] to create high economic value for humans is an important issue for consideration. On this basis, people proposed the theory of the circular economy, which relies on scientific model research to create economic development that is more in line with the concept of environmental management. Based on the theory of the circular economy, this paper analyses the scientific model of environmental management based on research on the mining development mode [9], the circular economy mechanism and green logistics. This paper summarises and proposes a development mode and mechanism for the mining circular economy based on the current mineral resource development and utilization situation and the environmental problems in China; the theory and the actual situation of resources and the environment at home and abroad are then combined.

\section{Research on the mining development mode and mechanism based on the circular economy}

\section{Ecological economy}

The ecological economy is based on ecological principles and a market economy, guided by the coordinated economic and environmental development of the modern economic system, economic theory and system engineering methods, and the use of modern science and technology to form a virtuous cycle of coordinated development for ecology and the economy [10] and achieve the economy, society, resources and environment. Its essence is to ensure natural reproduction on the basis of economic development, ecological bearing capacity and the expansion of economic reproduction to form a dense, efficient, sustainable and healthy natural socioeconomic ecosystem, optimise industrial structure, create a reasonable economic layout, constantly improve resource renewal and environmental carrying capacity, and increase economic strength.

\section{Circular economy}

Based on the efficiency of resources, the circular economy adopts the principle of "reduction, reuse and recovery" (3R principle) to use and recycle resources. This economic system can help China make more rational use of its resources and create greater value. It is characterised by closed loop material circulation and the utilization of energy cascades. Economic activity is dynamic in the circular economy. The circular economy combines the principles of ecology, economics and system theory, uses natural resources in an environmentally friendly way, improves the utilization rate of resources, fully coordinates the relationship between man and nature, contributes to social development, prepares for economic transcendence, and provides new schemes for protecting the ecological environment. The circular economy has the following characteristics: resource recycling [11], scientific management, low development, high utilization, the pursuit of economic, social and environmental benefits through coordination and unity, the development of economic growth model connotation, an environmental governance model to prevent the main issues, control over the whole process, and a green accounting system with evaluation indicators. 


\section{Sustainable development of mineral resources}

Sustainable mineral resource development [12] meets the needs of economic and social development and will not cause intolerable damage to the human environment, ecology, health and life. Its basic aim is to scientifically and rationally develop mineral resources, strive to coordinate the relationship between human beings and mineral resources, cherish and make full use of mineral resources while considering the interests of all future generations, and allocate mineral resources across generations and across regions [13] to meet the common needs of all generations and regions and realise resource sharing.

\section{Mining circular economy}

The mining circular economy refers to an economic system in which a closed-loop material flow economic system is formed according to the characteristics of mineral materials, the natural ecological law and the exploration, exploitation, production, deep addition and consumption of mineral products. The mining circular economy depends on the superposition of the internal energy flow and information flow to achieve the harmonious development of the global environment and social progress, and its core is the comprehensive development and utilization of mineral resources. In other words, the mining circular economy is a feedback [14] process involving mineral exploration, mineral resources, mineral products, renewal, and final harmless treatment. In the ongoing economic cycle, the rational and sustainable use of all minerals and energy can reduce the consumption of mineral resources and those mineral activities that affect the natural environment. "Low mining, high utilization, low emissions" can realise a small degree of interconnection to form a mineral exchange system that maximises the utilization of mineral and energy systems. Compared with the traditional mode of mineral resource utilization, the key link in the circular economy utilization mode is the change in the economic development chain from linear to circular through the recycling of resources.

\section{Green logistics research based on circular economy theory}

\section{Connotation of green logistics}

It is urgent and necessary that China implement and develop green logistics to achieve major progress in its logistics industry. The development of green logistics is of great significance for achieving social cost savings and alleviating the pressure of environmental pollution control. Logistics operations and management is the third profit source of the modern enterprise economy because of its potential profit space, and it has received increasing attention from society. Enterprise logistics and social logistics are developing vigorously, and great progress has been made in warehousing, transportation, distribution and many other aspects. However, with the vigorous development of logistics, many intermediate logistical links are also bringing environmental problems, such as the exhaust emissions of transport vehicles, the waste generated from storage, poor packaging and so on, which have different impacts on the environment. Green logistics aims to reduce environmental pollution and resource consumption through the use of advanced logistics technology and environmental management concepts applied to logistics system planning and logistics operations to realise green process control and management. To prevent damage to the environment in the logistics process, the logistics environment should be purified to make full use of logistics resources. 
With the tide of global economic integration, enterprise operation at the supply chain level has replaced the previous competitive pattern of a single enterprise. To adapt to the global operation of the supply chain, many traditional tariff and nontariff barriers have been gradually relaxed, while environmental barriers are becoming more prominent in competition. In a broad sense, green logistics controls and tracks the whole production process of products and ensures that it meets the relevant environmental protection policies and standards in the procurement, research and development, and sales stages to reduce the damage to the environment caused by the product manufacturing process from the perspective of the efficient utilization of resources. Therefore, its connotation includes energy conservation and environmental protection. In practice, some enterprises provide a list of prohibited materials to their cooperative raw material suppliers and refuse to use substances harmful to the environment. At present, people's understanding of the green supply chain tends to emphasise green products.

\section{Linkage between the regional economy and green logistics development}

(1) The regional economy is a strong support for promoting the development of green logistics. The outstanding features of green logistics are the rational utilization of resources and environmental protection, and it can serve as an important motivation for the further development of logistics. Regional economic theory breaks the traditional concepts, expands the boundary of logistics management research and management, and highlights the importance of resource conservation and sustainable utilization. At the same time, it provides stronger high-end scientific and technological support and strong financial support.

(2) Green logistics promotes the strengthening of the regional economy: green logistics can accelerate the implementation of manufacturing enterprises in specific fields to supply goods; it has a strong hierarchy [15], increases the speed with which goods travel from the original production, sales and distribution to customers, and pays attention to the implementation of efficient and rapid logistics modes. First, it is necessary to promote the development of the regional economy. When considering large-scale logistics enterprises, we should first consider reducing the transportation cost, as this occupies a large proportion of overall costs, improving customer satisfaction, shaping the ideal image of the enterprise in the public mind, reducing energy consumption to support environmental protection, and forming a more harmonious regional market economic atmosphere.

(3) The regional economy and logistics - green coordination and mutual aid: green logistics and local economic development have developed into a body providing mutual aid, and the two complement each other. Therefore, the existing logistics operation must rely on the local economic model to improve. At all levels, the management measures of each process node of the supply chain are related to optimising the setting and rational utilization of resources. In addition, supply chain development is strongly regional [16], and it has the characteristics of cross-regional and cross-national development. To minimise the damage to the ecological environment caused by logistics operations, we should strive to form an efficient and healthy logistics circulation system.

\section{Correlation analysis of the circular economy and green logistics}

As a national and humanised green movement, green logistics has been receiving increasing attention. Green logistics is a systematic project related to people's livelihood. It is the premise and the paving stone of sustainable economic development and an 
objective requirement if there is to be environmental protection for human development. In China, green environmental protection-inspired material research and development for the development of new energy, new fuel, and green logistics also has very large development space. Green logistics can be reflected in the whole lifecycle of goods, from the improvement of commercial links to the reduction in resources and consumables and to the recycling of waste.

China's logistics industry is facing problems such as high costs, wasted resources, serious environmental pollution, and a lack of mechanisms for allocating macrolevel logistics infrastructure. If China continues to adhere to this economic development model, it will inevitably lead to the destruction of the ecosystem, at which time, our home will be in a predicament. Circular economy and green logistics researchers proposed the idea of saving resources and promoting green logistics, with the basic goal of environmental protection. In the construction of a green economy, energy conservation and environmental protection infrastructure construction logistics play an increasingly important role. Waste disposal in transportation, warehousing, packaging and logistics has an important impact on the environment. Green logistics is the foundation for developing the Chinese economic transformation. China should strengthen the coordination of various transportation modes and transportation enterprises and encourage enterprises to speed up development of logistics products and packaging materials to make major contributions to resources and the environment. Therefore, the implementation of green logistics in China is inevitable, and there are many business opportunities.

Compared with the two, the scope of the circular economy is relatively large, requiring the development of all industries. China should prioritise resource conservation and environmental protection, including agriculture, industry and tertiary industry $[17,18]$. The recycling of resources plays an important role in industry, as it can not only protect the environment but also save resources, reflecting the concept of a green enterprise. The scope of green logistics is very small; importantly, it only considers the green and capital recycling of various system resources in the process of logistics development to save resources and protect the environment. Considering the similarities and differences between the circular economy and green logistics, we can see that their essence is the same.

\section{A circular economy promotes the development of green logistics}

To develop green logistics in China, it is necessary to take environmental issues as an important decision-making variable for enterprises; transform the entire supply chain to reduce the impact of pollution on the natural environment at every stage of production, packaging, transportation, distribution and use; establish a green supply chain system; and ensure the sustainable development of the logistics economy. Based on the "3Rs", the circular economy conducts a series of economic activities. It aims to reduce the input of natural resources, make efficient use of natural resources, and produce low, or even zero, emissions. Its core is to close the loop in material flows, and exists on three levels: the large cycle, small cycle and medium cycle. The small cycle refers to material circulation within an enterprise, and it thus falls within enterprise logistics, and the material circulation between enterprises.

The circular economy changes the internal production mode of enterprises through green logistics and forms internal circulation within enterprises. Enterprises design the production process, promote the recovery of raw materials and energy, enact clean production and green logistics, actively adopt ecological industrial technology and 
equipment, and design and transform the production process to form an ecological process with reduced or zero waste. The "wasted" upstream products become downstream products. To reduce or even avoid environmental pollution, enterprises should actively adopt eco-industrial technology and equipment for improved production process design and transformation. To achieve cleaner production and logistics activities within enterprises, we should focus on developing and applying green logistics technology, operating and implementing reverse logistics, and classifying, reusing and reasonably treating waste.

In the circular economy, circulation can occur in an industrial ecological park, or as an ecological cycle between industrial parks. Enterprises connect different industries to form a symbiotic combination of shared resources and by-products. Waste heat, waste water and waste become the raw materials or power used by another enterprise to produce their product, and their waste will become the raw materials or power for another enterprise to produce its own product. These products then become the raw materials or power for another enterprise to produce the first product. In this way, resources can be recycled. Finally, the inevitable residues will be discharged but will have zero emissions and be harmless to life and the environment. The circular economy has changed the traditional industrial combination and industrial layout. At this level of circulation, enterprises in different industries take "resources" as their cue and are connected through the gradual utilization of waste or by-products and energy.

\section{Mining and green logistics development model analysis}

\section{Analysis of the mining development mode}

Resources are the lifeblood of national development, the foundation of the people and a necessary condition for the development of heavy industry. If resources are not efficiently used, the production efficiency of enterprises will be reduced, and it will be difficult to maintain such enterprises in the long run. Mining resources are widely used. Aerospace, plastic, textile, automobile and other manufacturing industries cannot develop without the support and consumption of mining resources. A clear understanding of the national mining development model not only supports the state's ability to issue relevant policies and the government's ability to manage resources but also helps people realise the impact that the destruction of resources will have on our lives.

As the basic raw materials for the development of the national economy, not only are mineral resources in short supply but also, in their development and utilization, environmental pollution and solid waste are prominent problems. Therefore, the theory, mode and mechanism of a mining circular economy must be combined with practice, which will have strong practical significance and certain reference value for the relevant national departments.

\section{Analysis of the development mode of green logistics}

Green logistics is reflected not only in the distribution of products but also in the production, packaging and sales of products. Green logistics is both a positive development model and a reverse development model. Although the concept of green practices, recycling and environmental protection proposed by this mode is novel, it meets the development pace of the times. For enterprises, the mode can reduce the production cost of enterprises; for consumers, it can allow them to better enjoy the welfare brought by the commodity economy; for the country, the mode can better make full use of the country's 
material resources, embed the green concept into the hearts of the people, and help the national economy continue to improve steadily, It is believed that in the future, China's green logistics will increasingly improve, creating a leading global logistics development mode.

\section{Results and discussion}

\section{Mining development mode}

According to Figure 1, China's mineral resources account for only $13.5 \%$ of its total resources, power resources account for $25.6 \%$, coal resources account for $26.8 \%$, land resources account for $31.3 \%$, and other resources account for the remainder. These statistics show that China's mineral resources are still not up to the level of developed countries worldwide. Therefore, in China, which has limited resources and has been developing its national economy at the expense of those resources for decades, realising the highest value output for its resources and shortening the gap with developed countries is an urgent resource problem to be solved.

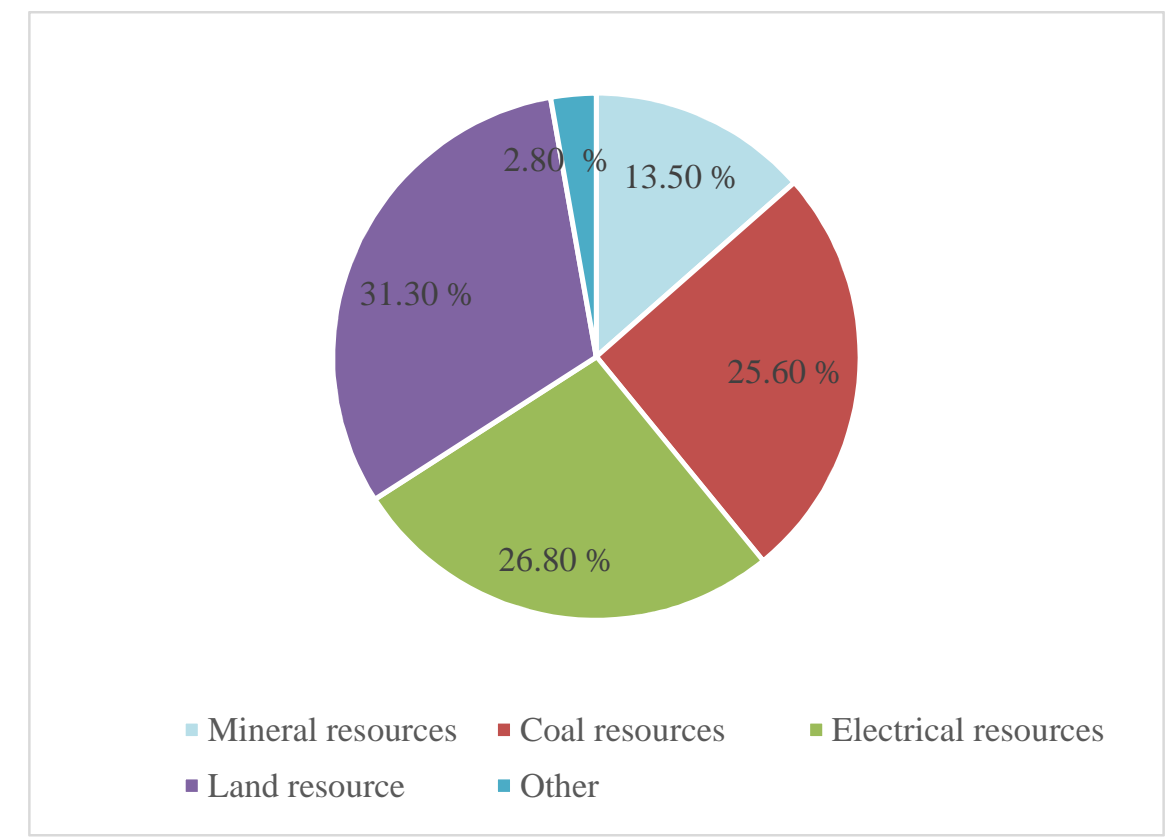

Fig. 1. Proportions of China's natural resources

Figure 2 shows that China's mineral resources are mainly distributed in coastal areas (the $\mathrm{Y}$ axis represents the proportion of coastal areas and inland areas), and their distribution is extremely unbalanced. For areas deep inland, not only are mineral resources in short supply, but economic development is also lagging. 




Fig. 2. Distribution of resources in China

The annual distribution of resources in China

Table 1

\begin{tabular}{|c|c|c|}
\hline Time [years] & Coastal areas mineral resources [-] & Inland areas mineral resources [-] \\
\hline 2015 & 0.38 & 0.62 \\
\hline 2016 & 0.40 & 0.60 \\
\hline 2017 & 0.44 & 0.56 \\
\hline 2018 & 0.47 & 0.53 \\
\hline 2019 & 0.49 & 0.51 \\
\hline
\end{tabular}

Distribution of resources in China is shown in Table 1. To solve the problem of resource distribution in China, we adopted the "south-north water diversion project", "west-east gas" and "China's lost" approaches. Although the problem of resource distribution has been solved to a certain extent, the waste of resources in the transmission process is inevitable, and $100 \%$ error-free transmission will not be achieved. Generally, China should make good use of its existing resources to resolve the uneven distribution of resources.

As shown in Figure 3, the environmental damage caused by mining in China is relatively serious (the Y-axis represents the percentage of mining's impact on the environment), the tailings stacking problem represents a large proportion, and the open-pit mining problem is also prominent, meaning that mining resources are facing unprecedented challenges. The benefits brought by mining resources should not be at the cost of destroying the environment but should be reasonably developed under environmentally friendly conditions in a way that will not damage economic development but will protect the environment in which we live. The promotion and implementation of circular economy theory can help mining resources create greater value, truly realise value for money, and effectively promote China's industry. 


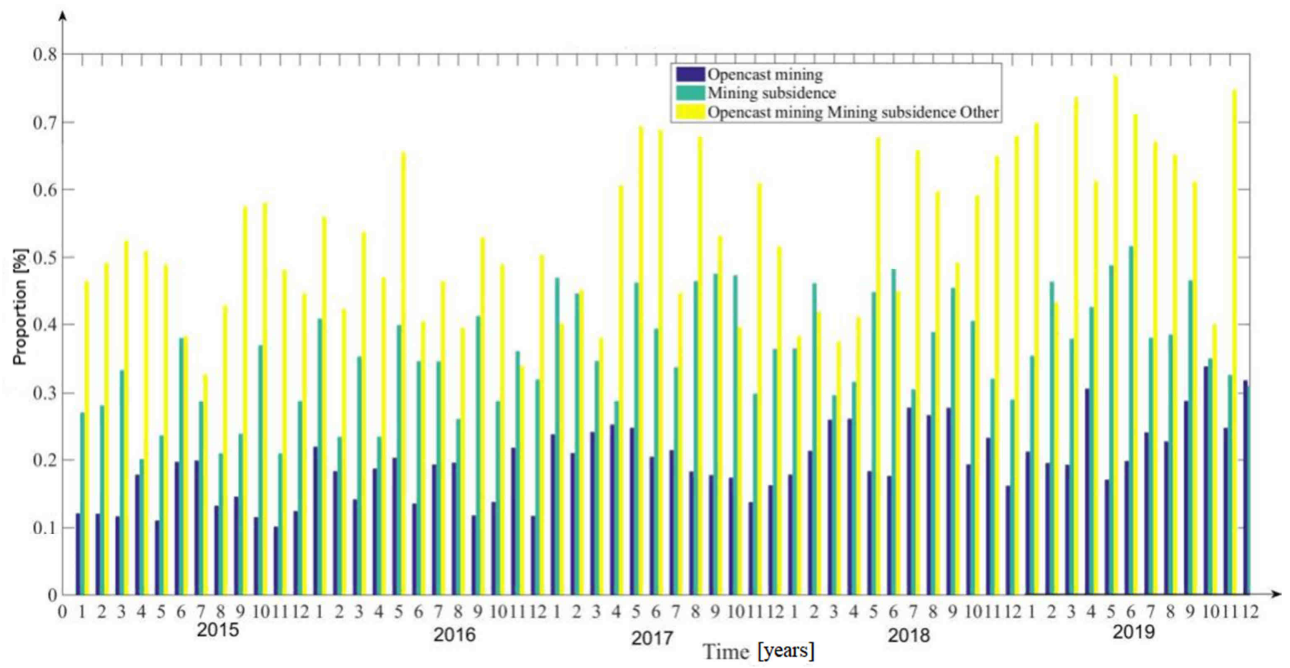

Fig. 3. Mining occupation and damage in China

\section{Development mode of green logistics}

Figure 4 shows that the output value of China's logistics industry has been consistently on the rise since 2015 (the Y-axis represents the growth output value of the logistics industry), when the output value was approximately 450 million yuan. The output value reached 590 million yuan in 2016 and 690 million yuan in 2017. The growth was the most obvious in 2018 , rising to 1.05 billion yuan, and the output value reached a new high of 1.18 billion yuan in 2019 .

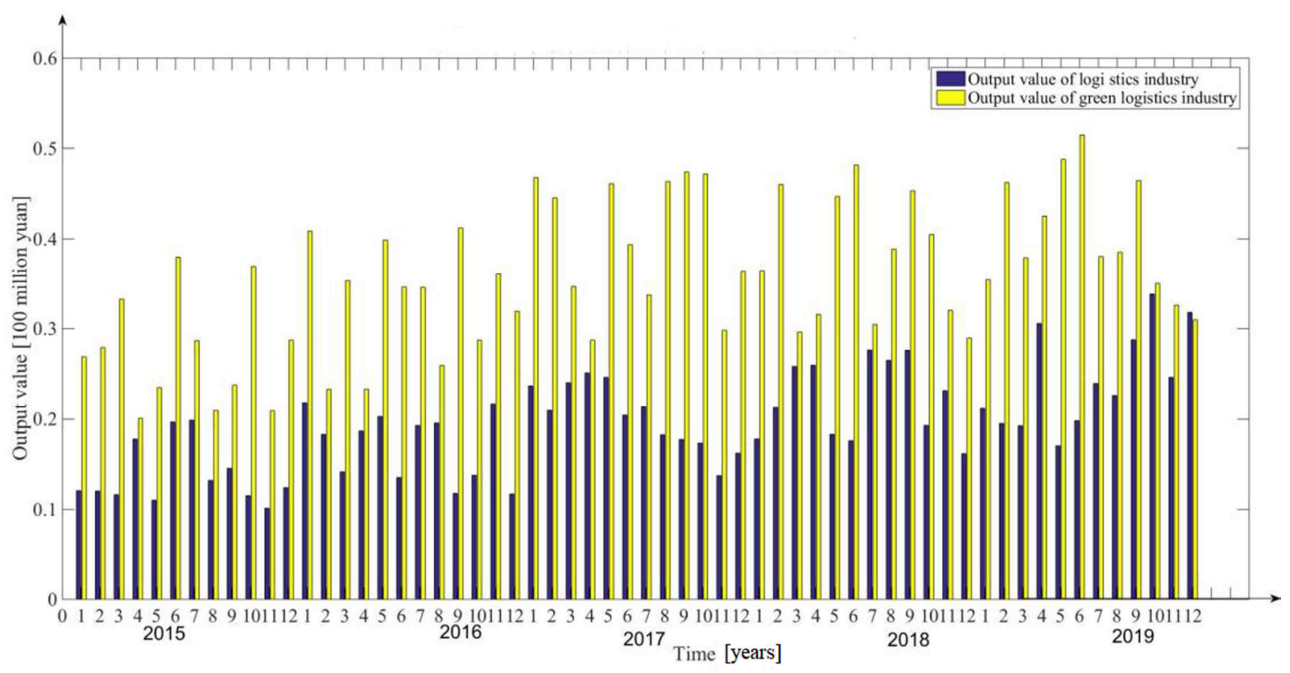

Fig. 4. Comparison of the output values of China's logistics industry and green logistics industry 
The growth of these figures shows that China's logistics industry has a very large production potential. The continuous breakthrough in its output value has led many people to see business opportunities and invest in the industry. The output value of the green logistics industry is also increasing year by year, which shows that green logistics will serve as a new logistics industry model with development potential. I believe that this mode will continue to improve and develop into the future.

\section{Conclusion}

The development of a mining recycling economy in China must occur at different levels and patterns. China's circulation mining economy needs corresponding constraints and incentive mechanisms if it is to develop, and much work must still be done to ensure the establishment of the mining recycle economy mode and mechanism, such as improving various statistical data, improving and perfecting the laws and regulations, etc., and establishing the appropriate level of science and technology. Due to time and ability limitations, the model of the mining recycling economy and the mechanistic study of the depth and breadth of mining needs to be strengthened. In particular, research on its mechanism is insufficiently thorough. To guarantee effective operation of the circular economy, many aspects need to be further explored and researched.

The circular economy has greatly influenced the development of the logistics industry, and green logistics have emerged. At present, all countries worldwide are prioritising the development of circular economies and green logistics. China has gradually carried out in-depth theoretical research and practice in this area and has many achievements and gained much experience. However, due to its late start in green logistics research and the relatively backward green logistics technology in China, green logistics management has not accumulated a large number of successful green logistics activities to form positive behaviours among enterprises and in society.

At present, China's resources are limited. Determining how to make use of limited material resources is of great economic value because it is important to continue to support human creation. The theory of the circular economy is based on environmental management and argues that by applying the scientific mode, you can create products that are more in accord with people's economic development. The complete embodiment of the circular economy is the circular economy of resources, which saves resources, utilises recycling and coordinates with environmental needs. The "renewable resource" cycle model has the characteristics of low development, high utilization and low emissions. In the continuing economic cycle, all material and energy can support reasonable and sustainable land use, minimising the influence of economic activities on the natural environment. This article considers the mining recycling economy development model and mechanism. Based on the theory of the circular economy, green logistics is studied within two patterns of environmental management science. Using statistical analysis, the typical analysis method and the comparative analysis method, and considering the exploitation and utilization of mineral resources and environmental problems in China, this article summarises the mining recycling economy development model and mechanism based on theory and on the actual situation of resources and the environment in China and abroad. This paper summarises the problems in China related to mineral resources and the environment. Combining the theory and reality of resource and environmental conditions, this paper proposes the mining mode and mechanism for circular economy development, 
which embodies innovation and has a certain reference value. Under the scientific environmental management mode, the theory of the circular economy will become more popular, and the national economy will again create new output value.

\section{References}

[1] Birch SP. From the linear economy to the circular economy: A basic model. Finanz Archiv Public Finance Analysis. 2017;74(1):71-87. DOI: 10.1628/001522118X15097191506475.

[2] Jiang X, Tian Z. Analysis of the factors affecting the sustainable use of pulp industry material resources in Guangxi province-based on the manager's perspective. Paper Asia. 2019;2(2):64-9. Available from: https://www.researchgate.net/publication/331972301_Analysis_of_the_factors_affecting_the_sustainable_ use_of_pulp_industry_material_resources_in_guangxi_province-based_on_the_manager's_perspective.

[3] Hankammer S, Brenk S, Fabry H, A Nordemann, Piller FT. Towards circular business models: Identifying consumer needs based on the jobs-to-be-done theory. J Cleaner Production. 2019;231:341-58. DOI: 10.1016/j.jclepro.2019.05.165.

[4] Fang S, Wang Y, Gou B, Yan X. Toward future green maritime transportation: An overview of seaport microgrids and all-electric ships. IEEE Trans Vehicular Technol. 2020;69(1):207-19. DOI: 10.1109/TVT.2019.2950538.

[5] Martins NO. The classical circular economy, sraffian ecological economics and the capabilities approach. Ecol Economics. 2018;145:38-45. DOI: 10.1016/j.ecolecon.2017.08.026.

[6] Liu J, Feng Y, Zhu Q, Sarkis J. Green supply chain management and the circular economy: Reviewing theory for advancement of both fields. Int J Physical Distribution Logistics Manage. 2018;48(8):794-817. DOI: 10.1108/IJPDLM-01-2017-0049.

[7] Rennie D. Make peer review scientific. Nature. 2016;535:31-3. DOI: 10.1038/535031a.

[8] Li Y, Ma C, Wang Y. Landslides and debris flows caused by an extreme rainstorm on 21 July 2012 in mountains near Beijing, China. Bull Eng Geol Environ. 2019;78(2):1265-80. DOI: 10.1007/s10064-017-1187-0.

[9] Shah VP, Behl CR, Flynn GL. Principles and criteria in the development and optimization of topical therapeutic products. J Pharmaceut Sci. 1992;6(1):72-80. DOI: 10.1159/000211090.

[10] Tao Z, Jing W, Xiaojiang W. Application of data mining technology in university information management. Agro Food Industry Hi Tech. 2017;28(1):1734-7. Available from: https://www.researchgate.net/publication/318680932_Application_of_data_mining_technology_in_ university_information_management.

[11] Sahoo HK, Behera B, Satapathy M, Behera SD. Sustainable rural livelihood security of small farmers through efficient resource recycling in crop-fish-poultry-mushroom based integrated farming system model. Int J Current Microbiol Appl Sci. 2019;8(12):1745-68. DOI: 10.20546/ijcmas.2019.812.210.

[12] Nauman S, Hussain N. Provision of human capital by business schools of Pakistan: A need for the sustainability of the Pakistani banking sector. J Education Business. 2017;92(1):44-52. DOI: 10.1080/08832323.2016.1274712.

[13] Sefako T, Walingo T. Biological resource allocation algorithms for heterogeneous uplink PD-SCMA NOMA networks. IEEE Access. 2020;8:194950-63. DOI: 10.1109/ACCESS.2020.2990119.

[14] Titkanloo HN, Keramati A, Fekri R. Proposing a new model to aggregate ratings in multi-source feedback approach based on the evidence theory. Soft Computing. 2020;24(11). DOI: 10.1007/s00500-019-04458-6.

[15] Salve AD, Pietro RD, Mori P, Ricci L. A logical key hierarchy based approach to preserve content privacy in decentralized online social networks. IEEE Trans Dependable Secure Computing. 2020;17(1):2-21. DOI: 10.1109/TDSC.2017.2729553.

[16] Ashiagbor D. Renewing the case for regionalism: EU transnational governance in an era of regulatory nationalism. German Law J. 2020;21(1):41-5. DOI: 10.1017/glj.2019.93.

[17] Wang W, Wang Q, Sohraby K. Multimedia sensing as a service (MSaaS): Exploring resource saving potentials of at cloud-edge IoT and fogs. IEEE Internet Things J. 2017;4(2):487-95. DOI: 10.1109/JIOT.2016.2578722.

[18] Tsai SB, Wang K. Using a novel method to evaluate the performance of human resources in green logistics enterprises. Ecol Chem Eng S. 2019;26(4):629-40. DOI: 10.1515/eces-2019-0045. 